\title{
Comprehensive validation of the FORMOSAT-7/COSMIC-2 electron density profiles and its application to space weather
}

\author{
I-Te Lee ${ }^{1,2,3, *}$, Jyun-Ying Huang ${ }^{2,4}$, Hsu-Hui Ho ${ }^{2,4}$, Wen-Hao Yeh ${ }^{5}$, and Mark Chia-Ping Cheng ${ }^{2}$ \\ ${ }^{1}$ Advanced Research Center for Earth Sciences, National Central University, Taoyuan City, Taiwan \\ ${ }^{2}$ Central Weather Bureau, Taipei City, Taiwan \\ ${ }^{3}$ Department of Space Science and Engineering, National Central University, Taoyuan City, Taiwan \\ ${ }^{4}$ Center for Atmospheric Resource and Disaster Studies, National Taiwan University, Taipei City, Taiwan \\ ${ }^{5}$ National Space Organization, National Applied Research Laboratories, Hsinchu County, Taiwan
}

\begin{abstract}
Article history:
Received 19 May 2021

Revised 20 December 2021

Accepted 30 December 2021
\end{abstract}

Keywords:

FORMOSAT-7/COSMIC-2, Radio occultation, Ionospheric profiles, Data assimilation, Space weather forecast

\section{Citation:}

Lee, I.-T., J.-Y. Huang, H.-H. Ho, W.H. Yeh, and M. C.-P. Cheng, 2021: Comprehensive validation of the FORMOSAT-7/COSMIC-2 electron density profiles and its application to space weather. Terr. Atmos. Ocean. Sci., 32, 1033-1045, doi: 10.3319/ TAO.2021.12.30.03

\begin{abstract}
The FORMOSAT-7/COSMIC-2 (F7/C2) mission can provide near 4000 soundings per day of the Earth's ionosphere by the TriG GNSS Radio occultation System (TGRS) onboard each satellite. The TGRS can receive signals from GPS as the FORMOSAT-3/COSMIC, and additional from GLONASS to increase measurements. In this paper, comprehensive validations of ionospheric electron density profiles, and results of data assimilation system are reported. First, co-located observations are used for self-comparison to prove that the payload is operating normally. Moreover, $\mathrm{F} 2$ region peak density $(\mathrm{NmF} 2)$ and peak height $(\mathrm{hmF} 2)$ estimated from ionosonde are served as a reference to evaluate the quality of data. The difference of electron density between Jicamarca and F7/C2 reveals a stable bias from 100 to $300 \mathrm{~km}$ altitude with slight overestimate. F7/C2 profiles are also highly correlated with worldwide ionosonde soundings, the correlation coefficients for $\mathrm{NmF} 2$ and $\mathrm{hmF} 2$ are 0.94 and 0.84 , respectively. The bias of $\mathrm{NmF} 2$ and $\mathrm{hmF} 2$ are around $10^{4} \mathrm{~cm}^{-3}$ and few kilometers, which indicates F7/C2 measurements are accurate and stable. Even the F7/ C2 satellites received signals at the lower orbital altitudes, they can obtain consistent performance of measurements. These dense observations can shorten the data accumulation period to reproduce three-dimensional ionospheric structure and make near real-time monitoring of ionospheric conditions possible. In addition, the data assimilation system is applied to analyze the impacts for ionospheric forecast. The results show significant improvement of the electron density distribution. Detailed validation and investigation are reported in this paper to prove that the profiles retrieved from $\mathrm{F} 7 / \mathrm{C} 2$ are reliable and suitable for operational space weather applications.
\end{abstract}

\section{INTRODUCTION}

The Earth's ionosphere comprises massive charged particles and can affect radio wave propagation. When radio waves transit through the ionosphere, the signals would be reflected or refracted depending on the plasma density, ionospheric structure, and frequency of the radio wave. This characteristic has been employed to explore and measure the morphology and variations in the ionosphere as well as the changes brought by space weather, lower atmosphere, and lithosphere of the Earth in the past few decades. Most

\footnotetext{
* Corresponding author

E-mail:itlee@jupiter.ss.ncu.edu.tw
}

instruments are built on the ground at an observatory or installed on a single spacecraft/satellite. Thus, it is difficult to accumulate sufficient observations to cover the entire globe with a suitable spatial and temporal resolution for the ionosphere since these measurements might be taken either only over a specified location or associated with the satellite orbits in space.

Since the 20th century, scientists have conducted occultation experiments to probe the atmosphere of a planet by recording the phase and amplitudes of the radio signals occulted by a planetary (Phinney and Anderson 1968). The first mission to measure the Earth's atmosphere is the 
Global Positioning System/Meteorology (GPS/MET) mission launched in 1995 (Ware et al. 1996; Kursinski et al. 1997). Subsequently, many missions have been designed to carry a radio occultation (RO) instrument onboard a single satellite. The FORMOSAT-3/COSMIC (F3/C) launched in 2006 was the first mission that deployed six microsatellites around the Earth to form a constellation for measuring the atmosphere and ionosphere using the RO technique. These satellites are operated in six separate orbital planes at about $800-\mathrm{km}$ altitude with a $72^{\circ}$ inclination angle. They receive radio signals from the Global Positioning System (GPS) to estimate the absolute total electron content (TEC) and then retrieve electron density profiles (EDPs) for scientists and operators to understand the ionosphere (Schreiner et al. 2007; Anthes et al. 2008). The research results and applications show the significant achievements of $\mathrm{F} 3 / \mathrm{C}$ and further pave a way for meteorology and space weather operation by RO technology. For instance, the Space Weather Operational Office (SWOO) of the Central Weather Bureau (CWB) used EDPs to monitor the global ionospheric conditions and forecast ionosphere-thermosphere status via a developed data assimilation system. The products are routinely published on the web page for the general public to provide information on the ionosphere for radio communication and satellite positioning usage. By the end of April 2020, there were more than 4.6 million ionospheric profiles measured by F3/C. After 14 years of operation, the daily amount is significantly dropped from a few thousand profiles to less than one hundred since the electrical power of satellites gradually degrades. Thus, it is difficult to accumulate observations for operations. Therefore, the National Space Organization (NSPO) of Taiwan officially announced that FORMOSAT-3's mission was completed on 1 May 2020.
With that successful experiences and contributions of operations, the NSPO and the National Oceanic and Atmospheric Administration (NOAA) of the United States (US) proposed a follow-on RO mission named FORMOSAT-7/ COSMIC-2 (F7/C2) for operational needs. Figure 1a depicts the six satellites of the F7/C2 mission at low earth orbit with orbital altitude and inclination angle of $520 \mathrm{~km}$ and $24^{\circ}$, respectively. These six satellites are numbered FS7_1,FS7_2, FS7_3, FS7_4, FS7_5, and FS7_6. The RO instrument onboard F7/C2 is the TriG GNSS Radio occultation System (TGRS) that can receive signals from both the US GPS and Russian Global Navigation Satellite System (GLONASS) to obtain RO measurements for the Earth's atmosphere and ionosphere. The six satellites of F7/C2 were successfully launched on 25 June 2019 at the Kennedy Space Center in the US by SpaceX's Falcon Heavy rocket. They are initially placed in a circular injection orbit of about $720 \mathrm{~km}$ altitude with an inclination angle of $24^{\circ}$. When releasing these satellites from the rocket, they are separated sequentially with 16-minute intervals to maintain enough distance between each satellite for ground mission control. Moreover, all six satellites will be sequentially descended to the mission orbit at $550 \mathrm{~km}$ every 3 months to separate their orbital planes by $60^{\circ}$. After about 18 months, F7/C2 will uniformly provide about 4,000 daily observations between $-45^{\circ}$ and $+45^{\circ}$ in latitude. This amount of observations will be four times that generally provided by F3/C in this latitude range. Moreover, the ionospheric data latency of $\mathrm{F} 7 / \mathrm{C} 2$ will be shortened to less than an hour, which is much faster than that of $\mathrm{F} 3 / \mathrm{C}$. These advantages are good for the space weather communities and the real-time ionospheric weather monitoring.

To evaluate the qualities and performances of FOMOSAT-7/COSMIC-2, the Taiwan Analysis Center of (a)

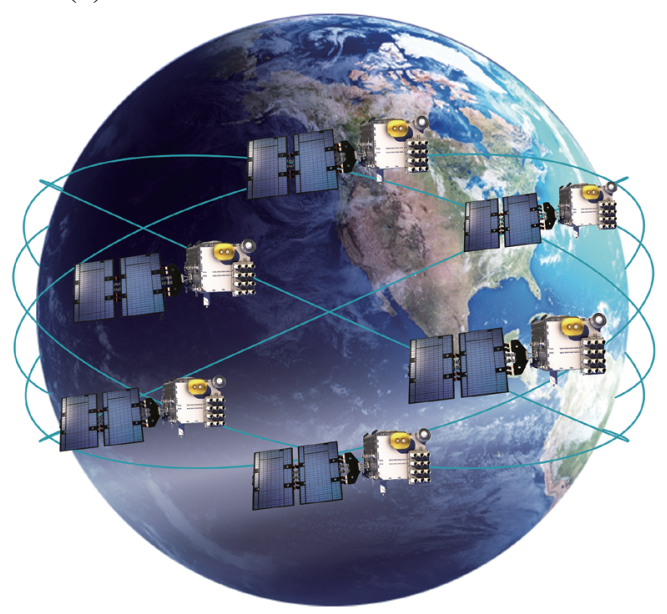

(b) C2E3 2019/07/16 (197) 03:44UT

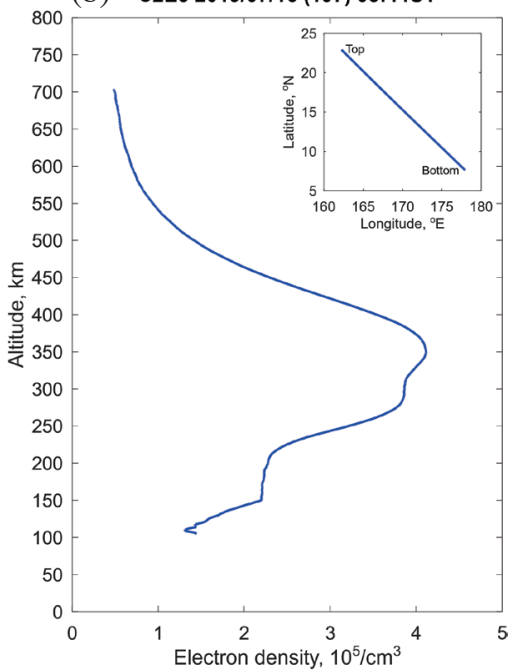

Fig. 1. FORMOSAT-7/COSMIC-2 (F7/C2) constellation and the first ionospheric electron density profile. (a) Six F7/C2 satellites in low-inclination orbits of about $24^{\circ}$ at $520-550 \mathrm{~km}$ altitude illustrated by National Space Organization. (b) The first ionospheric electron density profile of F7/C2 over the Pacific Ocean on 16 July in 2020. The locations of tangent points for this profile are illustrated in the upper right box. 
COSMIC (TACC) and SWOO have conducted various investigations since the first ionospheric electron density profile was retrieved. These investigations involve selfcomparison of each satellite during the early stage (from 16 July 2019 to 31 October 2019), validated with Jicamarca and worldwide ionosonde soundings served as independent references for data quality. Further, after three of the six satellites have been lowered down to mission orbit, another co-located comparison was made for evaluating RO profiles from different orbit altitudes. Finally, a preliminary improvement for daily ionospheric monitoring and ionospheric-thermosphere data assimilation system was illustrated to address the benefits of $\mathrm{F} 7 / \mathrm{C} 2$ for space weather applications. Summaries of these comprehensive validations and the evaluations of F7/C2 EDPs are described in this paper.

\section{PRELIMINARY COMPARISON}

After NSPO completed various subsystem investigations, the payloads of F7/C2 were activated, and they recorded the first occultation measurement on 16 July 2019. The data was downloaded to the ground station and then transmitted to two data processing centers, the US Data Processing Center (USDPC) of COSMIC Data Analysis and Archive Center (CDAAC) and Taiwan Data Processing Center (TDPC) of TACC, simultaneously to retrieve atmospheric and ionospheric profiles. Notably, the EDPs pro- vided by TDPC and USDPC were derived using the Abel inversion (cf. Hajj and Romans 1998) from the RO measurements similar to the $\mathrm{F} 3 / \mathrm{C}$ mission. The first ionospheric profile produced by TACC is shown in Fig. 1b, which displays a vertical structure of electron density with clearly E, $\mathrm{F} 1$, and F2 layers over the Pacific Ocean at about $173.53^{\circ} \mathrm{E}$ and $11.86^{\circ} \mathrm{N}$ around 15:30 LT (03:30 UT). To check the payload condition and quality of observations before delivering products to operational centers in real-time, calibration and validation are performed by comparison between F7/C2 satellites and independent ionosonde soundings during the early stage of the F7/C2 mission (from 16 July 2019 to 31 October 2019).

First, to evaluate the performance of the RO payload onboard each satellite, co-located profiles from different satellites are sought after all six TGRS are turned on. To identify the co-located measurements, occultation time within a time interval of \pm 30 -minute and horizontal separation of the maximum electron density location less than $0.25^{\circ}$. Figure 2 displays a particular case of six profiles obtained from six F7/C2 satellites that received signal from the same GNSS satellite, GPS PRN 05, around 13:30 UT on 21 July 2019. Although those F7/C2 satellites are slightly separated due to the deployment procedure, it could be considered that these satellites measure almost the same region of the ionosphere simultaneously. These observations are obtained sequentially by FS7_5, FS7_6, FS7_2, FS7_4,

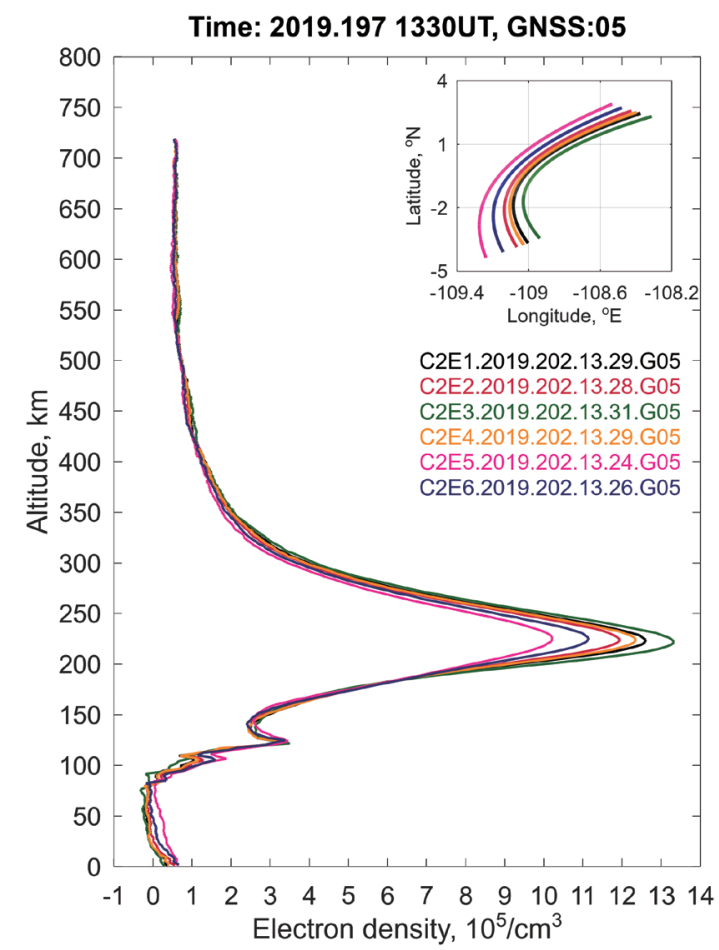

Fig. 2. Co-located ionospheric electron density profiles measured by six F7/C2 satellites on 21 July 2020. Colored lines represent measurements from each satellite from FS7_1 (C2E1) to FS7_6 (C2E6). The corresponding locations of tangent points for these six F7/C2 profiles are illustrated in the upper right box. 
FS7_1, and FS7_3. The tangent points of these measurements are projected from $-109^{\circ}$ to $-108^{\circ}$ in longitude and $-5^{\circ}$ to $4^{\circ}$ in latitude. Figure 2 reveals similar profiles from top-down to bottom with slight shifts at around the density peak altitude. They all also show a clear E layer feature near $125 \mathrm{~km}$. Nevertheless, the difference of peak density demonstrates that the longitudinal gradient resulted from the production of plasma near the local morning, at about 07:00 LT.

However, since the distances between each satellite widen after being launched, it is difficult to find sufficient cases with all six satellites observing simultaneously. Therefore, the measurements of FS7_1 are served as a reference to find other co-located profiles and estimate the bias corresponding to other satellites. The matched profiles are collected if the distance between two positions of the density peak is less than $0.25^{\circ}$ in longitude and latitude. In total, 280 cases are found, which are divided into 2, 4, 24, 20, and 230 cases of six, five, four, three, and two satellites co-located, respectively. These selected profiles are interpolated by cubic spline and resampled in height with $2-\mathrm{km}$ resolution. The bias is estimated by subtracting the profile of FS7_1 from the other co-located profiles. The result of measurement differences is shown in Fig. 3. The mean values of bias are almost zero from top to bottom with smaller standard deviations, except below about $150 \mathrm{~km}$. The standard deviation is near $2 \times 10^{3} \mathrm{~cm}^{-3}$ above $400 \mathrm{~km}$ and increases to near $4.5 \times 10^{3} \mathrm{~cm}^{-3}$ at around $225 \mathrm{~km}$. This proves that the TGRS onboard the F7/C2 satellites can measure the ionosphere with identical performance. The standard deviations correspond to the mean values and yield obvious fluctuation below $150 \mathrm{~km}$, which might be due to the inversion error or other reasons.

\section{VALIDATIONS}

After confirming that the systematic bias of $\mathrm{F} 7 / \mathrm{C} 2$ RO payloads is small, the measurements are compared with other reliable instruments to verify the ionospheric structure is compatible. The ionosonde located at the Jicamarca Radio Observatory, Peru, is considered a reference in this study. To find nearby profiles for this comparison, two criteria are defined: (1) the distance between the position of the RO peak density and the ionosonde station should be less than $2^{\circ}$ in longitude and latitude and (2) a time interval of 30-minute related to the ionosonde record is required. Thus, 115 profiles are selected during the early stage. Figure 4a demonstrates the ionogram and profile of true height analysis of Jicamarca at 14:30 UT on 14 October 2019. The ionogram reveals clear traces of Es, F1, and F2 layers of the ionosphere as well as the automatically scaled trace and true height profiles. Figure $4 \mathrm{~b}$ illustrates the FS7_2 profile satisfied the criteria with the Jicamarca profile as a co-located example. Meanwhile, the FS7_2 profile also reveals a similar structure to the Jicamarca ionosonde measurement. These co-located observations are resampled in high with $5-\mathrm{km}$ resolution, and calculated difference by subtracting the Jicamarca measurements from the F7/C2 profiles. The overall difference between $\mathrm{F} 7 / \mathrm{C} 2$ profiles and Jicamarca ionosonde is shown in Fig. 5. It demonstrates that RO measurement is slightly overestimated than ionosonde, but it still shows a stable bias and standard deviation

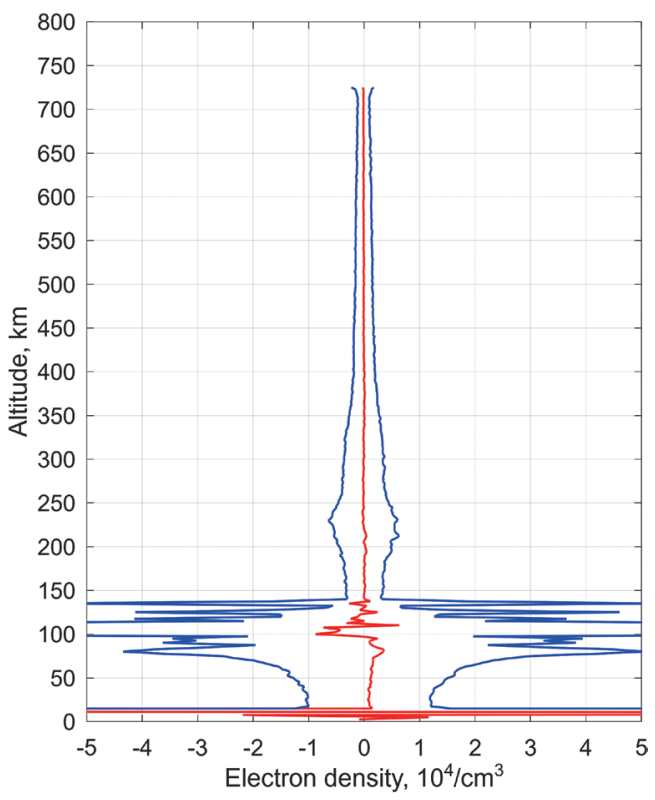

Fig. 3. Statistical comparison of electron density profiles for all co-located F7/C2 RO soundings from 2019/07/16 to 2019/10/31. The red line indicates the mean of difference, and the blue lines are the standard deviations. 


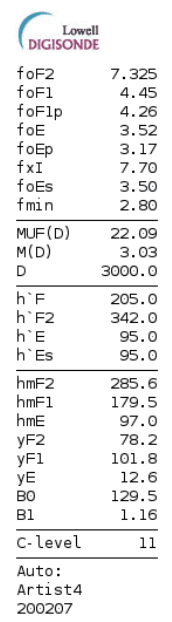

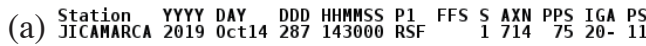

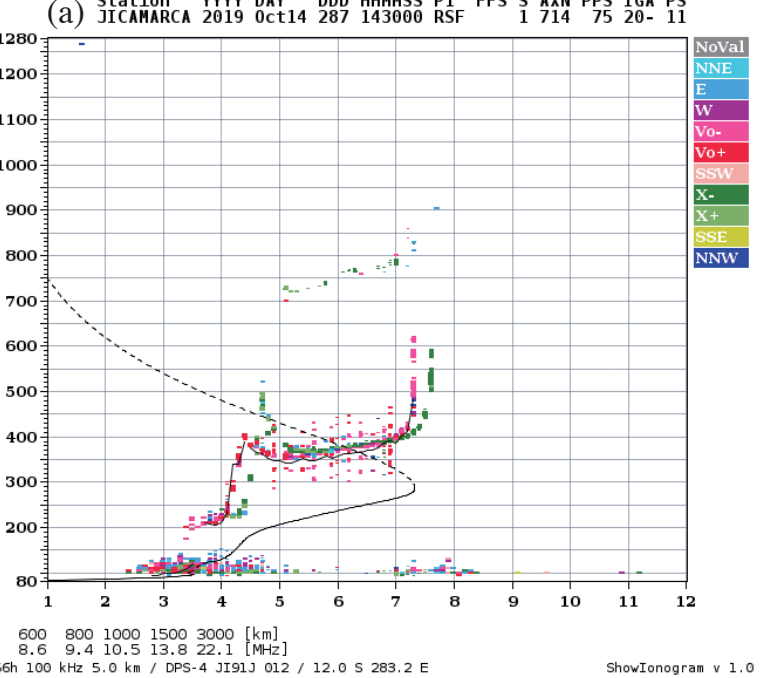

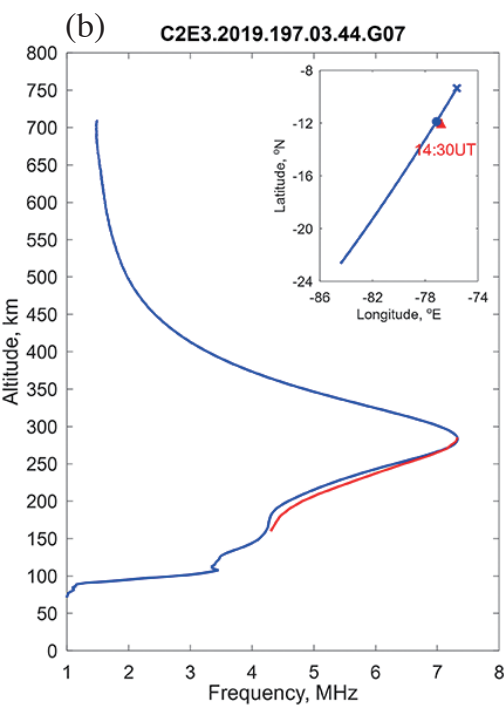

Fig. 4. An example of comparison with Jicamarca ionosonde observation. (a) The ionogram of Jicamarca ionosonde at 14:30 UT on 2019/10/14. It downloaded from Lowell digisonde database (https://giro.uml.edu/didbase/). (b) The co-located F7/C2 electron density profile (blue) and ionogram derived electron density profile (red). In the upper right box, the Jicamarca ionosonde is indicated by red triangle. The ground tracks of RO tangent points are illustrated by blue line. The cross is the lowest altitude of RO profile, and the blue dot is location of the peak density.

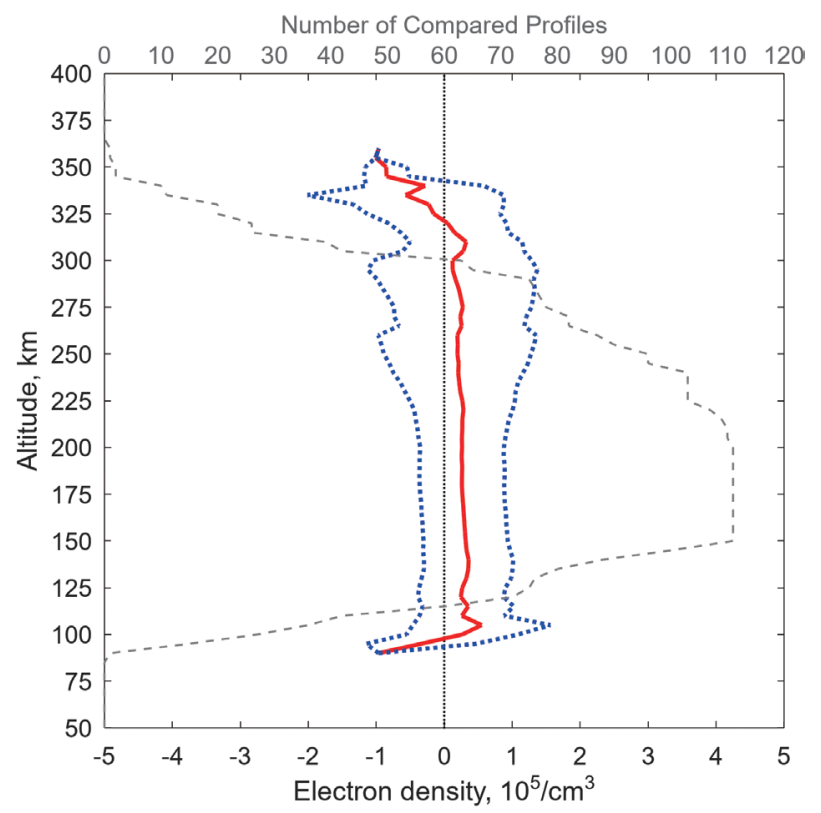

Fig. 5. Statistical comparison of F7/C2 electron density profiles with Jicamarca observations during the early stage. The red line indicates the mean of difference, and the dotted blue lines are the standard deviations. The dashed black line represents the number of observations at various altitudes. 
from 100 to $300 \mathrm{~km}$ altitude, about $2.5 \times 10^{4} \mathrm{~cm}^{-3}$ and $8.0 \times$ $10^{4} \mathrm{~cm}^{-3}$, respectively. Notably, the number of evaluated profiles quickly decreased above $300 \mathrm{~km}$ for the topside ionosphere and below $150 \mathrm{~km}$ for the ionospheric $\mathrm{E}$ region due to the sounding limitation for ionosonde.

This single station validation shows that the $\mathrm{F} 7 / \mathrm{C} 2$ measurements can generally describe a bottom-side ionospheric structure efficiently. To extensively validate $\mathrm{F} 7 / \mathrm{C} 2$ profiles at various longitudes and latitudes, the global ionosonde data are acquired from the Digital Ionogram Database (DIDBase) operated by Lowell Global Ionospheric Radio Observatory (GIRO) Data Center of the University of Massachusetts Lowell (UML). More detailed information about GIRO is described by Reinisch and Galkin (2011). The observation network of GIRO comprises 105 stations globally, but only 41 of these can be used for this validation due to the distribution of F7/C2 measurements. The locations of these stations are shown in Fig. 6. The DIDBase provides two major reliable parameters of ionosonde soundings: the ionospheric F2 layer peak electron density (NmF2), which is converted from the F2 layer critical frequency (foF2), and the peak height (hmF2). It is good to use $\mathrm{NmF} 2$ and $\mathrm{hmF} 2$ to evaluate the quality of F7/C2 measurements. Notably, the $\mathrm{NmF} 2$ and $\mathrm{hmF} 2$ provided by DIDBase are derived from ionograms using ARTIST, an Automatic Real-Time Ionogram Scaler with True height (Reinisch et al. 1983). ARTIST also provides a value named autoscaling confidence score (Galkin et al. 2013) for each record. To avoid some absurd values, which might result from the uncertainties of the autoscaling method, the quality control of the ionosonde soundings is filtered by this score. The confidence score varies from 0 to 100 , corresponding to a confidence level of autoscaling. In this study, only records with an autoscaling confidence score of more than 70 are qualified and used to evaluate the $\mathrm{F} 7 / \mathrm{C} 2$ measurements.

During the early stage, there are 121884 ionospheric profiles retrieved from $\mathrm{F} 7 / \mathrm{C} 2 \mathrm{RO}$ measurements as displayed in Fig. 6. The selecting criteria are the same as those described in the previous section with an additional one: the peak height of RO profile should exist between 150and $450-\mathrm{km}$ altitude to avoid error determination due to the Es layer. Based on these three criteria, 1637 profiles were matched for comparison with ionosonde soundings. Shown in Fig. 7, the correlation coefficient and bias are estimated to simplify and represent the general results of this validation. The correlation coefficient, bias, and standard deviation of $\mathrm{NmF} 2$ are $0.9395,-1.173 \times 10^{4} \mathrm{~cm}^{-3}$, and $8.539 \times$ $10^{4} \mathrm{~cm}^{-3}$, respectively. The RO measurements would slightly underestimate for electron density around the F2 peak altitude. These values indicate that RO measurements of F7/C2 generally comprise ionosonde soundings for the ionospheric $F_{2}$ peak density. By contrast, these values of $h m F 2$ are $0.8382,3.35 \mathrm{~km}$, and $23.93 \mathrm{~km}$, which also roughly agree with the ionosonde soundings, yielding a slightly lower cor- relation coefficient and higher standard deviation than that of the $\mathrm{NmF} 2$.

For more detailed investigation, the evaluation is further divided by the number of $\mathrm{F} 7 / \mathrm{C} 2$ satellites to confirm the consistency of measurements from each satellite. The correlation coefficients, biases, and standard deviations of $\mathrm{NmF} 2$ and hmF2 are listed in Table 1. Results of each satellite yield similar values to the overall results, which also indicate that all $\mathrm{F} 7 / \mathrm{C} 2$ satellites can provide measurements without significant difference.

Moreover, the RO payload of F7/C2 is designed to receive GNSS signals from the two major systems: GPS and GLONASS. It provides a good opportunity to evaluate measurements retrieved from signals of these two systems. The previous evaluations are further divided into two groups of signals. In general, the correlation coefficients of GPS and GLONASS are, respectively, 0.9402 and 0.9561 for NmF2, and 0.8361 and 0.8610 for $\mathrm{hmF} 2$. The other values of bias and standard deviation do not yield obvious inconsistency between these two GNSS signals, even after further division by six satellites. This result confirms that the profiles retrieved by receiving signals from either GPS or GLONASS agree well with the ionosonde soundings and demonstrate reasonably accuracy in $\mathrm{NmF} 2$ and $\mathrm{hmF} 2$.

\section{ALTITUDINAL COMPARISON}

Based on the deployment procedure of $\mathrm{F} 7 / \mathrm{C} 2$, the six satellites are sequentially descended from parking orbit at an altitude of about $720 \mathrm{~km}$ to the mission orbit at around $520 \mathrm{~km}$ in 18 months. During this transition period, the RO measurements are taken at these two different orbit altitudes. Meanwhile, the EDPs are started from the corresponding highest measurement, at around 720 and $520 \mathrm{~km}$, and retrieved downward by Abel inversion method. This provides a good opportunity to evaluate the performance of RO EDPs retrieved from these two altitudes. Since the RO payloads are turned off while the satellite is transferring orbit, observations are collected after the third satellite, FS7 4, completed its orbital transfer at the end of March 2020. There are 72868 profiles collected for April 2020 that when a half satellites have already lowered down to the mission orbit and the rest of them are still at the parking orbit. The EDPs measured by FS7_1, FS7_2, and FS7_4 are at orbits around $520 \mathrm{~km}$, the others are at $720 \mathrm{~km}$. Owing to the relative positions of $\mathrm{F} 7 / \mathrm{C} 2$ satellites and GNSS satellites, it is difficult to find co-located profiles to estimate the difference between each satellite. Therefore, these profiles are validated with ionosonde soundings from DIDBase, as described in the previous section.

There are 272 and 252 profiles selected for the mission and parking orbits, respectively. The correlation coefficients, biases, and standard deviations of these two orbits are estimated and listed in Table 2. The values of each orbit are 


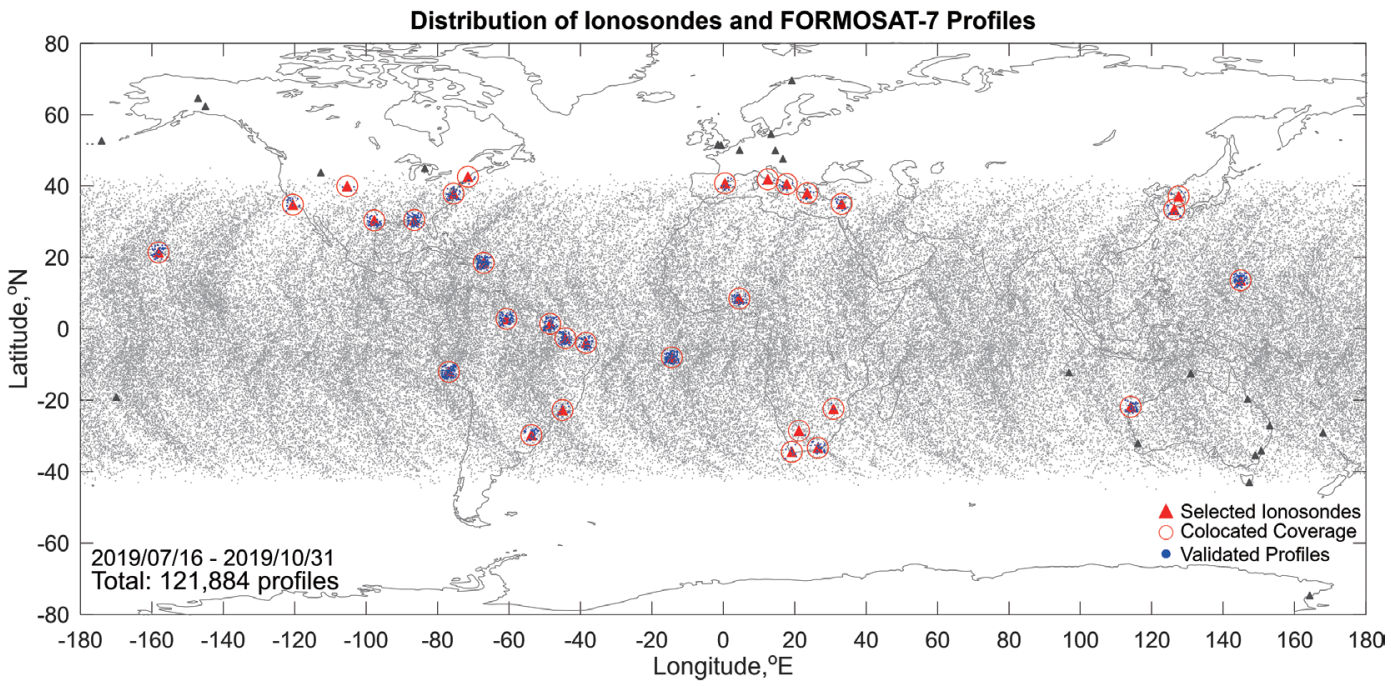

Fig. 6. Map of Ionosonde stations from GIRO and data distribution of the F7/C2 ionospheric profiles from 2019/07/16 to 2019/10/31. The triangles indicate the locations of GIRO ionosondes and the dots indicate the locations of F7/C2 profiles. The red triangles are the selected ionosondes, and the blue dots are validated RO profiles. Red circle is used to simply denote the coverage based on the selected criteria.
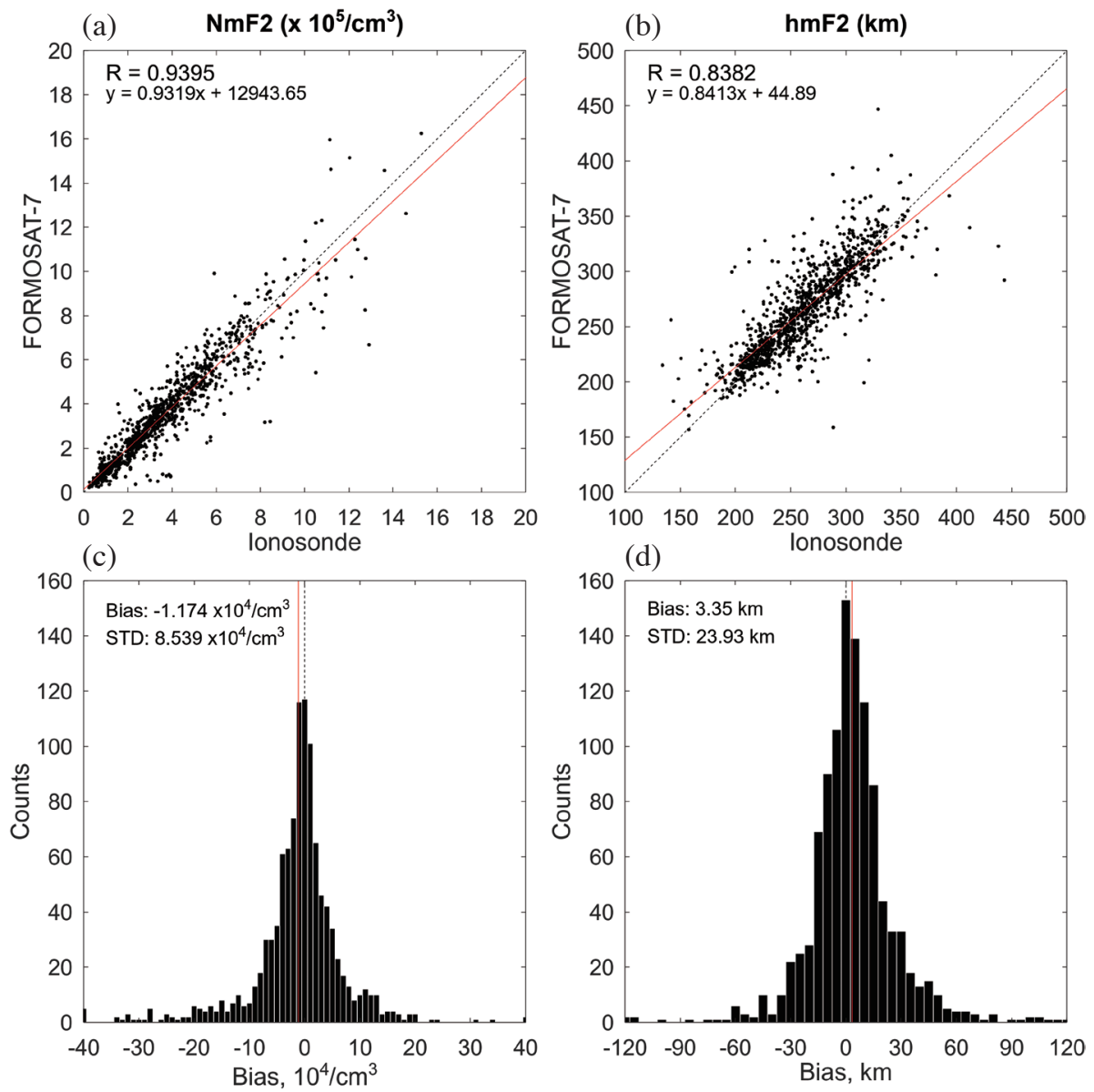

Fig. 7. Comparisons of F7/C2 ionospheric electron density profiles with the ionosondes. (a) Scatter plots and correlation coefficient of RO profiles and ionosonde soundings for $\mathrm{NmF}$. The red line indicates the linear regression fit. (b) Similar to (a), scatter plot and correlation coefficient for $\mathrm{hmF2}$. (c) Bias distributions for $\mathrm{NmF} 2$ with a bin width of $10^{4} \mathrm{~cm}^{-3}$. The red line indicates the mean of bias, the dashed black line is zero. (d) Similar to (c), the bias distributions for hmF2 with a bin width of $5 \mathrm{~km}$. 

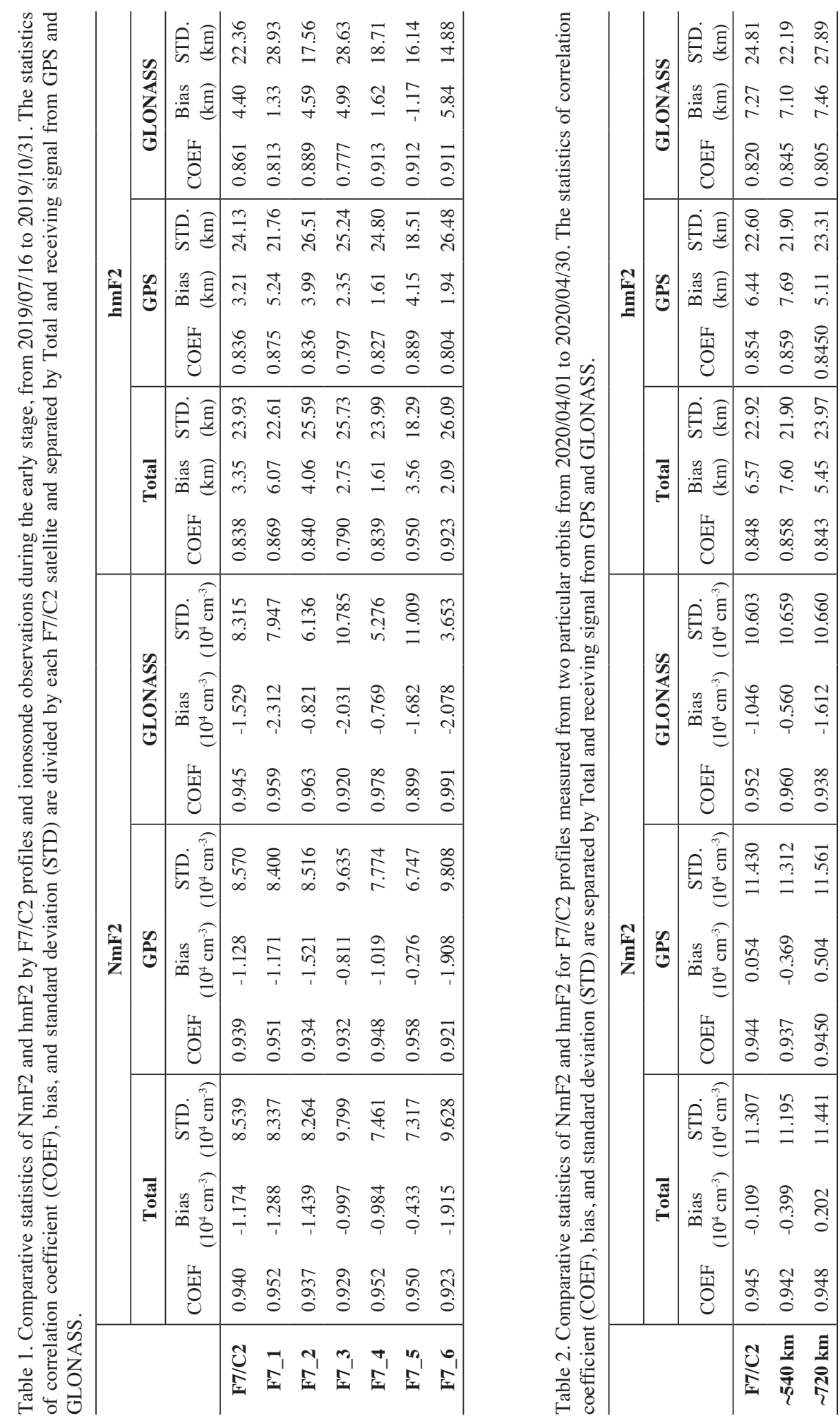
divided into two groups of GPS and GLONASS. The results only show slight differences in correlation coefficient, bias, and standard deviation of both $\mathrm{NmF} 2$ and hmF2. The results further indicate that the orbital altitudes do not influence the performance of RO soundings. Generally, the correlation coefficients of $\mathrm{NmF} 2$ and hmF2 agree with the values of the early stage shown in the previous section. The averaged bias of $\mathrm{NmF} 2$ reduces by $90 \%$, from $-1.173 \times 10^{4} \mathrm{~cm}^{-3}$ to $-0.109 \times 10^{4} \mathrm{~cm}^{-3}$, but the standard deviation increases by 1.5 times that of the early stage. Meanwhile, the bias and the standard deviation of $\mathrm{hmF} 2$ are similar to those of the early stage. The values of $\mathrm{NmF} 2$ and $\mathrm{hmF} 2$ also indicate that $\mathrm{RO}$ measurements generally underestimate the peak density and overestimate the peak height for these two orbits.

\section{APPLICATION OF SPACE WEATHER}

Since F7/C2 can provide more dense observations at low and equatorial latitudes, it would contribute more to space weather monitoring and forecasting. For near realtime monitoring purposes, TACC has published high-level products of the atmosphere and ionosphere by accumulating occultation observations to reconstruct the neutral temperature at a specified pressure level as well as NmF2 and hmF2 of the ionosphere. The previous global products collect observations within 3 hours period to accumulate an adequate amount based on data distribution and the number of $\mathrm{F} 3 / \mathrm{C}$ observations. By contrast, the latest version can reconstruct similar products by accumulating F7/C2 observations within only an hour This demonstrates that the F7/C2 observations can dramatically shorten the accumulating period; hence, it is sufficient and valuable to be used for near real-time atmospheric and ionospheric monitoring. The high-level products are produced every hour and published by TACC via its web page (https://tacc.cwb.gov.tw/v2/high qview.html).

On the other hand, SWOO operates an ionospheric forecast system by assimilating worldwide ground-based GNSS TEC observations and ionospheric RO EDPs into the National Center for Atmospheric Research (NCAR) Thermosphere-Ionosphere Electrodynamic General Circulation Model (TIE-GCM) since 2015. A more detailed description of this ionospheric data assimilation system is given in previous studies (Matsuo and Araujo-Pradere 2011; Lee et al. 2012, 2013; Hsu et al. 2014; Chartier et al. 2016; Chen et al. 2016). Observation simulation system experiments (OSSEs) have been performed in some studies (Lee et al. 2013; Hsu et al. 2018) to investigate the advances of ionospheric weather forecasts while assimilating the dense RO profiles into a numerical model before F7/C2 was launched. Results of these OSSEs all reported significant improvements in nowcasting and forecasting after assimilating worldwide distributed profiles. These studies suggested that the numerical space weather forecast could be advanced by assimilating F7/C2 EDPs in the future. Thus, SWOO set up two identical data assimilation systems, one without assimilating any observation to serve as a control, and another with assimilating TEC and F7/C2 RO profiles simultaneously to verify the contribution of RO data. The daily operation of SWOO mainly assimilated ground-based TEC because there are only a few profiles obtained by $\mathrm{F} 3 / \mathrm{C}$ during this investigating period. All experiments were executed routinely from 1 March to 30 April 2020. During this particular period, the F7/C2 satellites were more uniformly separated to provide observations globally than that during the early stage. Assimilated results are evaluated by the same method with ionosonde soundings.

The evaluated result of the experiment which assimilated TEC and F7/C2 EDPs is shown in Fig. 8. The correlation coefficient, bias, and standard deviation for $\mathrm{NmF} 2$ are $0.8468,1.208 \times 10^{4} \mathrm{~cm}^{-3}$, and $13.699 \times 10^{4} \mathrm{~cm}^{-3}$. These values of hmF2 are $0.7655,37.51 \mathrm{~km}$, and $27.52 \mathrm{~km}$. The correlation coefficients, biases, and standard deviations of the other two experiments for $\mathrm{NmF} 2$ and $\mathrm{hmF} 2$ were also estimated and listed in Table 3 . The boundary of the latitudinal region is set to $40^{\circ}$ in the northern and southern hemispheres. As the results show, the control run reveals that TIE-GCM could reproduce roughly ionospheric electron density globally with a correlation coefficient of about 0.75 for $\mathrm{NmF} 2$ and hmF2. Once GNSS TEC is assimilated into the system, the results yield the opposite behavior of density and altitude adjustments. According to the number of coefficients, the TEC observations would improve the electron density of TIE-GCM quantitatively to close the ionosonde soundings. Nevertheless, the results of hmF2 are degraded and worse than the control run. This might result from the imprecise error covariance value between TEC and altitudinal distribution. The assimilation results of F7/C2 RO profiles show an additional increment in correlation coefficients and a reduction in the bias and standard deviation of peak density. The F7/C2 RO profiles could provide the vertical structure of ionospheric electron density and further adjust the peak height closer to reality than the other two experiments. By contrast, the experiment which assimilated F7/C2 RO profiles can yield a better agreement of hmF2 and $\mathrm{NmF} 2$ with ionosonde soundings. In the higher latitude regions, these values are also improved with a similar magnitude as the middle and lower latitude regions. They do not reveal clear differences between the two regions, although most F7/C2 measurements are roughly in the middle and lower latitude regions.

\section{DISCUSSION}

After more than one year of the FORMOSAT-7/ COSMIC-2 launching, SWOO and TACC of CWB have performed various validations and evaluations to ensure the performance of RO payload and quality of ionospheric measurements by $\mathrm{F} 7 / \mathrm{C} 2$. In this study, comprehensive 
validations of F7/C2 RO EDPs are performed, and the corresponding results are reported. First, all six F7/C2 satellites demonstrate similar precision and quality of measurements without large differences in self-comparison. The validation result with the Jicamarca ionosonde shows a near-constant bias for the bottom-side ionosphere with slight overestimation of electron density. Although the retrieved ionospheric profiles could be lower than $100 \mathrm{~km}$ and even further extend to near the ground surface, the self-comparison yields larger uncertainty below $150 \mathrm{~km}$ altitude. Therefore, these values of extremely lower altitude might be imprecise and need careful evaluation before using.

For the worldwide ionosonde validations, the correlation coefficient of $\mathrm{NmF} 2$ and $\mathrm{hmF} 2$ shown in this study is 0.9395 and 0.8382 , which is similar to that reported by Liu et al. (2010). Their correlation coefficient of $\mathrm{NmF} 2$ and $\mathrm{hmF} 2$ by comparing $\mathrm{RO}$ profiles of $\mathrm{F} 3 / \mathrm{C}$ with measurements of the digisonde portable sounder (DPS) at Jicamarca is about 0.95 and 0.83 , respectively. Araujo-Pradere et al. (2019) pointed out the ionospheric parameters estimated by the ARTIST might have errors and need careful quality control. How- ever, Lin et al. (2020) reported the preliminary validation by manually scaled ionosonde soundings, and presented the correlation coefficients for $\mathrm{NmF} 2$ and $\mathrm{hmF} 2$ are both 0.885 . In this study, the validation results by autoscaling with confidence scores are similar to their reports. These autoscaled parameters do not lead errors for this validation when the confidence score is considered. In addition, validation of RO EDPs of the FengYun $3 \mathrm{C}$ mission presented by Yang et al. (2018) show that the correlation coefficient of $\mathrm{NmF} 2$ and $\mathrm{hmF} 2$ is 0.96 and 0.85 . The other RO EDPs obtained by the first China Seismo-Electromagnetic Satellite was validated with ionosonde and one incoherent scatter radar by Wang et al. (2020), who obtained the correlation coefficient of NmF2 and hmF2 is 0.9448 and 0.8357 of their results. Therefore, the performance of $\mathrm{F} 7 / \mathrm{C} 2$ is consistent very well with the reports of other RO missions.

Even the correlation coefficient of $\mathrm{hmF} 2$ is lower than that of $\mathrm{NmF} 2$, but the standard deviation of hmF2 is clearly less than $50 \mathrm{~km}$, approximately the ionospheric $e$ folding scale height around the density peak height. Therefore, this validation with worldwide ionosondes could be used to
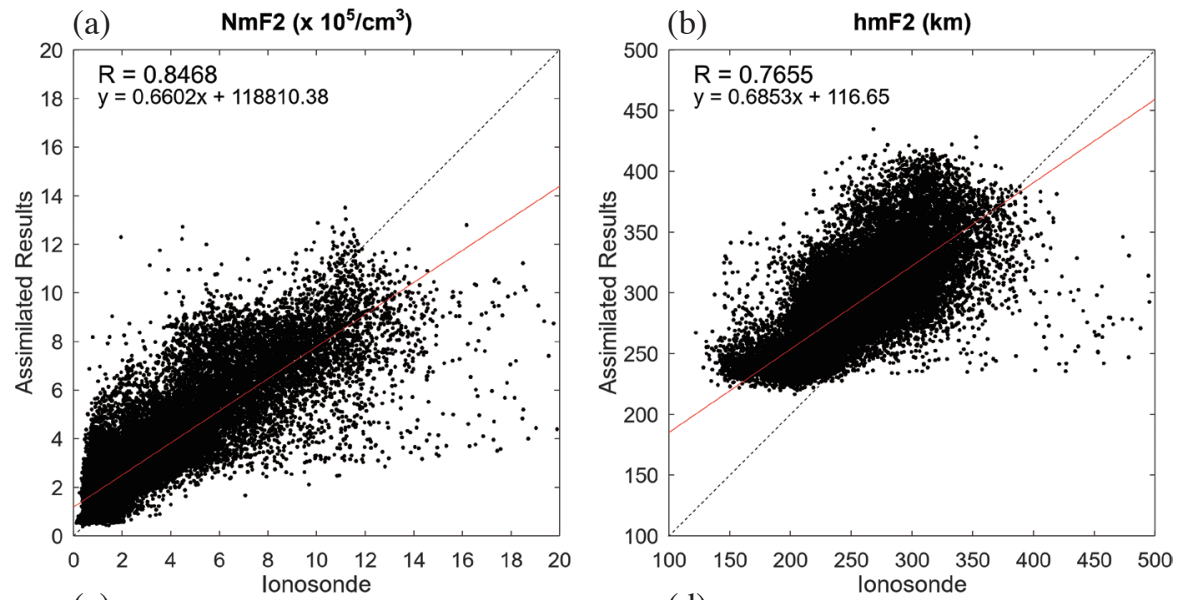

(c)
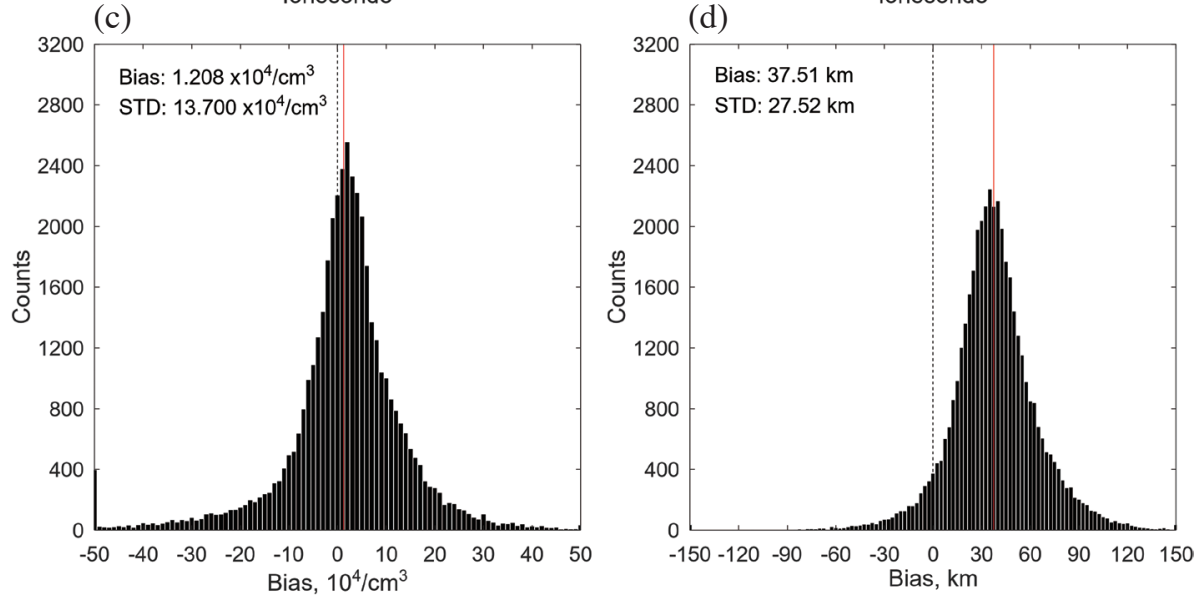

Fig. 8. Comparisons of assimilated results with the ionosondes. (a) Scatter plots and correlation coefficient of assimilated results and ionosonde soundings for NmF2. The red line indicates the linear regression fit. (b) Similar to (a), scatter plot and correlation coefficient for hmF2. (c) Bias distributions for $\mathrm{NmF} 2$ with a bin width of $10^{4} \mathrm{~cm}^{-3}$. The red line indicates the mean of bias, the dashed black line is zero. (d) Similar to (c), the bias distributions for hmF2 with a bin width of $2.5 \mathrm{~km}$. 


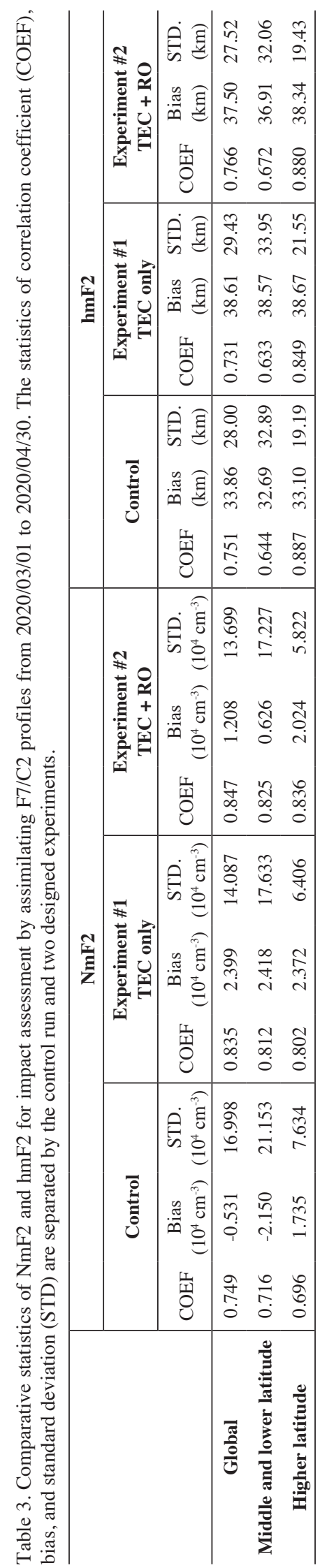

prove the quality and reliability of the $\mathrm{F} 7 / \mathrm{C} 2$ ionospheric profiles. Moreover, Liu et al. (2010) pointed out that RO measurements overestimate $\mathrm{NmF} 2$ at mid-latitude, but underestimate $\mathrm{hmF} 2$ and $\mathrm{NmF} 2$ in the EIA region. In this study, the biases of $\mathrm{hmF} 2$ and $\mathrm{NmF} 2$ indicate $\mathrm{F} 7 / \mathrm{C} 2 \mathrm{RO}$ measurements generally overestimate for altitude but underestimate for electron density. However, these values of bias for $\mathrm{NmF} 2$ and $\mathrm{HmF} 2$ are small, and would not affect data quality significantly.

Furthermore, the F7/C2 is the first operational constellation that can receive both GPS and GLONASS signals to measure the Earth's atmosphere and ionosphere by the RO scheme. The results of validation are further divided into two groups of GNSS to prove that the performances of retrieved EDPs using two different GNSS constellations are consistent. In some cases, the correlation and bias of GLONASS are better than that of GPS. Generally, data retrieved from the GPS and GLONASS are without system differences and can be directly merged for ionospheric space weather applications.

Further, the altitudinal comparisons reveal that the RO measurements retrieved from different altitudes would not cause essential discrepancies. The standard deviations of $\mathrm{NmF} 2$ in April 2020, were slightly higher than values during the early stage, which might have resulted from fewer of validated profiles. The correlation coefficient and bias of $\mathrm{NmF} 2$ are similar to those of the early stage. Notably, it is difficult to estimate the bias between the co-located profiles taken at the two orbits in more detail. For those selected profiles, the locations of maximum density are co-located, but the locations of tangent points might be far away from the peak altitude due to the relative positions between F7/C2 satellites and GNSS satellites. Thus, these co-located profiles received signals that penetrated through different areas of the ionosphere, except near the location of the density peak. This could result in the profiles displaying dissimilar structures of electron density above and below the peak.

The assimilated result indicates that the amount of electron density is improved globally when solely assimilating ground-based TEC observations. Nevertheless, it also points out that hmF2 became worse if only TEC observations were assimilated. By additionally assimilating F7/C2 EDPs into the system, the model performance can be better than the control run. Lee et al. (2013) reported F7/C2 could reduce the RMSE by about $4 \%$ than the control experiment by OSSE. In this study, the results reveal an obvious improvement of $\mathrm{NmF} 2$ and $\mathrm{hmF} 2$ after assimilating real observations, which well agree with previous studies. This once again proves that $\mathrm{F} 7 / \mathrm{C} 2 \mathrm{RO}$ profile can produce a reliable density structure of the ionosphere and further adjust the model to reality, such as those of previous OSSE studies. On the other hand, although the RO profiles are roughly distributed within $-40^{\circ}$ to $40^{\circ}$, the assimilated results also show improvements in the higher latitudes. It might have 
resulted from two reasons. The first one is that some profiles measured by higher orbit altitude are possibly distributed beyond that latitude boundary; these profiles would further make improvement in the higher latitude region. The other possibility is the assimilation system using the localization function can limit innovation surrounding observations during the regression step. As Lee et al. (2013) reported, the localization function applied in this system is given by the Gaspari and Cohn (1999) function with a half-width of about $10^{\circ}$ in the horizontal and $200 \mathrm{~km}$ in the vertical (cf. Lee et al. 2012). In other words, the radius of the impact area is about $20^{\circ}$ in a circular shape. Therefore, even RO profiles occurring near $-40^{\circ}$ or $40^{\circ}$ latitude can also adjust the model state variables beyond the latitudinal boundary and result in further improvements in the higher latitude.

\section{SUMMARY}

After the FORMOSTA-3/COSMIC demission in May 2020, the FORMOSAT-7/COSMIC-2 has taken the important place of the operational constellation to provide RO measurements for the Earth's atmosphere and ionosphere. More than one year after launch, the F7/C2 is operated normally and fully deployed on the mission orbit. It can provide near 4000 soundings per day for the ionosphere on average by receiving signals from GPS and GLONASS. In general, the $\mathrm{F} 7 / \mathrm{C} 2$ provides more than two times $\mathrm{RO}$ soundings than F3/C. By contrast, the soundings of F3/C are distributed globally, but the soundings of $\mathrm{F} 7 / \mathrm{C} 2$ are mainly distributed within $-40^{\circ}$ to $40^{\circ}$ latitude. Thus, the F7/ $\mathrm{C} 2$ can measure the lower and equatorial ionosphere four times frequently than the $\mathrm{F} 3 / \mathrm{C}$ mission. This would possibly assist to resolve signatures of atmospheric tidal effects, solar flux influences, and geomagnetic disturbances with shortened date accumulation period.

In this study, comprehensive validations of $\mathrm{F} 7 / \mathrm{C} 2$ ionospheric electron density profiles have been performed by comparison with independent ionosondes worldwide during various periods. These validations confirm that the F7/ $\mathrm{C} 2$ can provide ionospheric EDPs reliable and accurate for middle and lower latitudes. Dense observations with short data latency can reproduce the ionospheric structure within a shortened data accumulation period to make it possible for monitoring ionospheric space weather in near real-time. The SWOO and TACC not only applied F7/C2 measurements for space weather monitoring but also assimilated them into the ionosphere-thermosphere coupling model to produce forecasting information. According to the model results, the performance of numerical ionosphere-thermosphere forecasting is significantly improved by assimilating the EDPs of F7/C2. The vertical structure of ionospheric electron density additionally adjusts the density altitudinal distribution of the model. In the future, these measurements would be used to understand the structure and morphology of the ionospheric space weather and conduct monitoring and forecasting products for radio communication, satellite positioning, and other possible usages.

The released ionospheric products of FOMOSAT-7/ COSMIC-2 can be downloaded from the Taiwan Data Processing Center of TACC (https://tacc.cwb.gov.tw/v2/download.html) and the US Data Processing Center of CDAAC (https://www.cosmic.ucar.edu/what-we-do/cosmic-2/data/) simultaneously and freely.

Acknowledgements This study was performed by Taiwan Analysis Center of COSMIC and Space Weather Operational Office and are supported by National Space Organization grants NSPO-S-108249 and NSPO-S-109302, as well as Central Weather Bureau grants to National Central University and National Taiwan University, 1082206A and 1092291B, respectively. The authors acknowledge Digisonde owner organizations and Global Ionosphere Radio Observatory to collect, quality control, interpret, and store ionograms and ionogram derived data for public dissemination (http://spase.info/SMWG/Observatory/GIRO). The derived data of GIRO are available at DIDBase (https://giro. uml.edu/didbase/scaled.php), and the Jicamarca ionogram and the derived data used for this study can be obtained from its local database (https://www.igp.gob.pe/observatorios/radio-observatorio-jicamarca/?page id=9439) and DIDBase (https://giro.uml.edu/didbase/). The observational data from ground-based GPS receivers are streamed from International GNSS Services. The authors also thank the team of NSPO for operating and controlling the FORMOSAT-7/COSMIC-2.

\section{REFERENCES}

Anthes, R. A., P. A. Bernhardt, Y. Chen, L. Cucurull, K. F. Dymond, D. Ector, S. B. Healy, S.-P. Ho, D. C. Hunt, Y.-H. Kuo, H. Liu, K. Manning, C. McCormick, T. K. Meehan, W. J. Randel, C. Rocken, W. S. Schreiner, S. V. Sokolovskiy, S. Syndergaard, D. C. Thompson, K. E. Trenberth, T.-K. Wee, N. L. Yen, and Z. Zeng, 2008: The COSMIC/FORMOSAT-3 mission: Early results. Bull. Amer. Meteorol. Soc., 89, 313-334, doi: 10.1175/BAMS-89-3-313. [Link]

Araujo-Pradere, E., E. C. Weatherhead, P. B. Dandenault, D. Bilitza, P. Wilkinson, C. Coker, R. Akmaev, G. Beig, D. Burešová, L. J. Paxton, M. Hernández-Pajares, J.-Y. Liu, C. H. Lin, J. B. Habarulema, and V. Paznukhov, 2019: Critical issues in ionospheric data quality and implications for scientific studies. Radio Sci., 54, 440-454, doi: 10.1029/2018RS006686. [Link] Chartier, A. T., T. Matsuo, J. L. Anderson, N. Collins, T. J. Hoar, G. Lu, C. N. Mitchell, A. J. Coster, L. J. Paxton, and G. S. Bust, 2016: Ionospheric data assimilation and forecasting during storms. J. Geophys. Res., 121, 
764-778, doi: 10.1002/2014JA020799. [Link]

Chen, C. H., C. H. Lin, T. Matsuo, W. H. Chen, I. T. Lee, J. Y. Liu, J. T. Lin, and C. T. Hsu, 2016: Ionospheric data assimilation with thermosphere-ionosphere-electrodynamics general circulation model and GPS-TEC during geomagnetic storm conditions. J. Geophys. Res., 121, 5708-5722, doi: 10.1002/2015JA021787. [Link]

Galkin, I. A., B. W. Reinisch, X. Huang, and G. M. Khmyrov, 2013: Confidence score of ARTIST-5 ionogram autoscaling. INAG Technical Memorandum, 7 pp.

Gaspari, G. and S. E. Cohn, 1999: Construction of correlation functions in two and three dimensions. $Q$. J. R. Meteorol. Soc., 125, 723-757, doi: 10.1002/ qj.49712555417. [Link]

Hajj, G. A. and L. J. Romans, 1998: Ionospheric electron density profiles obtained with the global positioning system: Results from the GPS/MET experiment. Radio Sci., 33, 175-190, doi: 10.1029/97RS03183. [Link]

Hsu, C.-T., T. Matsuo, W. Wang, and J.-Y. Liu, 2014: Effects of inferring unobserved thermospheric and ionospheric state variables by using an Ensemble Kalman Filter on global ionospheric specification and forecasting. J. Geophys. Res., 119, 9256-9267, doi: 10.1002/2014JA020390. [Link]

Hsu, C.-T., T. Matsuo, X. Yue, T.-W. Fang, T. Fuller-Rowell, K. Ide, and J.-Y. Liu, 2018: Assessment of the Impact of FORMOSAT-7/COSMIC-2 GNSS RO Observations on Midlatitude and Low-Latitude Ionosphere Specification: Observing System Simulation Experiments Using Ensemble Square Root Filter. J. Geophys. Res., 123, 2296-2314, doi: 10.1002/2017JA025109. [Link]

Kursinski, E. R., G. A. Hajj, J. T. Schofield, R. P. Linfield, and K. R. Hardy, 1997: Observing Earth's atmosphere with radio occultation measurements using the Global Positioning System. J. Geophys. Res., 102, 2342923465, doi: 10.1029/97jd01569. [Link]

Lee, I. T., T. Matsuo, A. D. Richmond, J. Y. Liu, W. Wang, C. H. Lin, J. L. Anderson, and M. Q. Chen, 2012: Assimilation of FORMOSAT-3/COSMIC electron density profiles into a coupled thermosphere/ionosphere model using ensemble Kalman filtering. J. Geophys. Res., 117, A10318, doi: 10.1029/2012JA017700. [Link]

Lee, I. T., H. F. Tsai, J. Y. Liu, C. H. Lin, T. Matsuo, and L. C. Chang, 2013: Modeling impact of FORMOSAT-7/ COSMIC-2 mission on ionospheric space weather monitoring. J. Geophys. Res., 118, 6518-6523, doi: 10.1002/jgra.50538. [Link]

Lin, C.-Y., C. C.-H. Lin, J.-Y. Liu, P. K. Rajesh, T. Matsuo,
M.-Y. Chou, H.-F. Tsai, and W.-H. Yeh, 2020: The Early Results and Validation of FORMOSAT-7/COSMIC-2 Space Weather Products: Global Ionospheric Specification and Ne-Aided Abel Electron Density Profile. J. Geophys. Res., 125, e2020JA028028, doi: 10.1029/2020JA028028. [Link]

Liu, J.-Y., C.-C. Lee, J.-Y. Yang, C.-Y. Chen, and B. W. Reinisch, 2010: Electron density profiles in the equatorial ionosphere observed by the FORMOSAT-3/COSMIC and a digisonde at Jicamarca. GPS Solut., 14, 75, doi: 10.1007/s10291-009-0150-3. [Link]

Matsuo, T. and E. A. Araujo-Pradere, 2011: Role of thermosphere-ionosphere coupling in a global ionospheric specification. Radio Sci., 46, RS0D23, doi: 10.1029/2010RS004576. [Link]

Phinney, R. A. and D. L. Anderson, 1968: On the radio occultation method for studying planetary atmospheres. J. Geophys. Res., 73, 1819-1827, doi: 10.1029/ ja073i005p01819. [Link]

Reinisch, B. W. and I. A. Galkin, 2011: Global ionospheric radio observatory (GIRO). Earth Planets Space, 63, 377-381, doi: 10.5047/eps.2011.03.001. [Link]

Reinisch, B. W., R. R. Gamache, J. S. Tang, and D. F. Kitrosser, 1983: Automatic real time ionogram scaler with true height analysis - ARTIST. AFGLTR-83-0209, AD A135174, University of Lowell, Center For Atmospheric Research, 31 pp.

Schreiner, W., C. Rocken, S. Sokolovskiy, S. Syndergaard, and D. Hunt, 2007: Estimates of the precision of GPS radio occultations from the COSMIC/FORMOSAT-3 mission. Geophys. Res. Lett., 34, L04808, doi: 10.1029/2006GL027557. [Link]

Wang, X., D. Yang, Z. Zhou, W. Cheng, S. Xu, and F. Guo, 2020: Validation of CSES RO measurements using ionosonde and ISR observations. Adv. Space Res., 66, 2275-2288, doi: 10.1016/j.asr.2020.08.028. [Link]

Ware, R., M. Exner, D. Feng, M. Gorbunov, K. Hardy, B. Herman, Y. Kuo, T. Meehan, W. Melbourne, C. Rocken, W. Schreiner, S. Sokolovskiy, F. Solheim, X. Zou, R. Anthes, S. Businger, and K. Trenberth, 1996: GPS Sounding of the Atmosphere from Low Earth Orbit: Preliminary Results. Bull. Amer. Meteorol. Soc., 77, 19-40, doi: 10.1175/1520-0477(1996)077<0019:GSO$\mathrm{TAF}>2.0 . \mathrm{CO} ; 2$. [Link]

Yang, G., Y. Sun, W. Bai, X. Zhang, C. Liu, X. Meng, Y. Bi, D. Wang, and D. Zhao, 2018: Validation results of $\mathrm{NmF} 2$ and hmF2 derived from ionospheric density profiles of GNOS on FY-3C satellite. Sci. China Technol. Sci., 61, 1372-1383, doi: 10.1007/s11431-0179157-6. [Link] 